\title{
Simplified numerical modelling of rectangular concrete-filled steel columns, beams and beam-columns
}

\author{
Z. Tao ${ }^{a *}$, U. Katwal ${ }^{a}$, M. K. Hassan ${ }^{a}$ and W. D. Wang \\ ${ }^{a}$ Centre for Infrastructure Engineering, Western Sydney University, Penrith, NSW 2751, Australia \\ ${ }^{b}$ School of Civil Engineering, Lanzhou University of Technology, Lanzhou 730050, China \\ *corresponding author, e-mail address: z.tao@westernsydney.edu.au
}

\begin{abstract}
Because of its computational efficiency, simplified numerical modelling is the preferred method to simulate structural frames for routine design. As for concretefilled steel tubular (CFST) columns, fibre beam element (FBE) modelling is often used in the simplified simulation. However, the accuracy of FBE modelling is greatly affected by the accuracy of the input material models, which should directly account for the interaction between the steel tube and core concrete. In this paper, simple yet accurate material models of steel and concrete are proposed for rectangular CFST columns by utilising a large amount of numerical data generated from detailed three-dimensional finite element modelling of stub columns. The material models are then incorporated into the simplified FBE simulation of rectangular CFST columns, beams and beam-columns. The accuracy of the simplified FBE simulation is verified by a wide range of experimental results on rectangular CFST stub columns, slender columns, beams and beam-columns.
\end{abstract}

Keywords: Concrete-filled steel tubes; simplified simulation; confined concrete; local buckling; columns; beam-columns.

\section{Introduction}

Concrete-filled steel tubular (CFST) columns have been widely used in modern construction because they offer many structural as well as economic benefits [1] Although CFST columns with circular crosssection provide the strongest confinement to the core concrete, CFST columns with square or rectangular cross-sections are still increasingly used in construction due to the ease in the design of beam-to-column connections, high cross-sectional bending stiffness and the aesthetic considerations [1].

Because of its computational efficiency, simplified numerical modelling is the preferred method of simulating structural frames for routine design. Regarding CFST columns, fibre beam element (FBE) modelling is often used in the simplified simulation. However, the accuracy of such FBE modelling is greatly affected by the accuracy of the input material models, which should directly account for the interaction between the steel tube and core concrete, including the concrete confinement and buckling of the steel tube.

There are a few steel and concrete stress versus strain $(\sigma-\varepsilon)$ models available in the literature developed for FBE modelling of square and rectangular CFST columns [2-5]. However, the majority of those material models are empirical and primarily derived from experimental data. They may give reasonable predictions within their validity ranges, but may not properly reflect the interaction between the steel tube and core concrete because the strength contributions from the steel and concrete core are not obtained explicitly. Meanwhile, the validity of an empirical model is restricted to the test data range used to derive the model parameters. Since there are increasing interests in using high-strength steel and concrete materials as well as thin-walled tubes, there is a strong need to develop simple yet accurate steel and 
concrete models to cover a wide range of parameters for CFST columns.

To address the above research need, Katwal et al. [6] has recently proposed effective steel and concrete $\sigma-\varepsilon$ models for circular CFST columns. This paper is a continuation of the previous work conducted by Katwal et al. [6]. The main aim of this study is to propose material models for rectangular CFST columns by utilising a large amount of numerical data generated from detailed three-dimensional (3D) finite element (FE) modelling of stub columns. The material models will then be incorporated into the simplified FBE simulation of rectangular CFST columns, beams and beam-columns. A wide range of experimental results on rectangular CFST stub columns, slender columns, beams and beam-columns will be utilised to verify the prediction accuracy of using the proposed material models.

\section{Finite Element Modelling}

The 3D FE model developed by Tao et al. [7] has been successfully used by Katwal et al. [6] to generate numerical data of circular CFST stub columns to cover a wide range of parameters. Based on regression analysis of these numerical data, Katwal et al. [6] developed effective $\sigma-\varepsilon$ models for $\mathrm{FBE}$ modelling of circular CFST stub columns. The accuracy of the FBE modelling has been verified by comparing the numerical results with experimental results.

The above approach adopted by Katwal et al. [6] will also be used in this study to develop effective $\sigma-\varepsilon$ material models for square and rectangular CFST columns. The numerical simulations (including 3D FE and FBE analyses) were conducted using ABAQUS software. For the FBE modelling, the material models were implemented in ABAQUS through a UMAT subroutine. More details about the 3D FE modelling and FBE modelling of CFST columns can be found in Tao et al. [7] and Katwal et al. [6] respectively.

\section{Development of Material Models For Fibre Beam Element Modelling}

For a rectangular (square is a special case) CFST column under axial compression, interaction can be developed between the steel tube and concrete, resulting in the development of confinement to the concrete [7]. This confinement effect might lead to an increase in strength and ductility for the core concrete. However, this effect varies to a great extent depending on various column parameters, such as the cross-sectional dimensions of the steel tube (width $B$, height $H$ and thickness $t$ ), steel yield stress $\left(f_{\mathrm{y}}\right)$ and unconfined concrete cylinder strength $\left(f_{\mathrm{c}}^{\prime}\right)$. Meanwhile, tensile hoop stresses developed in the steel tube will reduce its load-carrying capacity in the axial direction [5]. Furthermore, local buckling of the rectangular steel tube can occur during the loading process, which also affects the interaction between the steel tube and concrete. The combined influence of all these factors is very complex and should be properly considered when proposing material models.

To develop effective steel and concrete $\sigma-\varepsilon$ models, 3D FE models were built for rectangular CFST stub columns covering a wide range of column parameters $\left(f_{\mathrm{y}}=186-960\right.$ $\mathrm{MPa}, f_{\mathrm{c}}^{\prime}=20-200 \mathrm{MPa}$ and $\left.B / t=10-150\right)$. For each analysed example, the loads carried by the steel tube and core concrete were extracted from the middle section of the CFST column to generate "averaged" $\sigma-\varepsilon$ curves for the steel and concrete. Since the averaged $\sigma-\varepsilon$ curves have already incorporated the influence of interaction between the steel tube and concrete, they can be directly used in FBE modelling. Based on the numerical data, regression analysis is then conducted to propose effective steel and concrete models as described in the following subsections.

\subsection{Steel Material Model}

\subsubsection{Characteristics of stress-strain curves for steel}

In conducting 3D FE modelling of rectangular CFST stub columns, Tao et al. [7] adopted an elastic-perfectly plastic model for the steel. To reveal the influence of steelconcrete interaction on the effective $\sigma-\varepsilon$ curves of steel, typical columns with different confinement factors varied from 0.15 to 3.40 were analysed using the 3D FE modelling. The confinement factor defined in Tao et al. 
[7] is expressed as $\xi_{\mathrm{c}}=A_{\mathrm{s}} f_{\mathrm{y}} / A_{\mathrm{c}} f_{\mathrm{c}}{ }^{\prime}$, where $A_{\mathrm{s}}$ and $A_{\mathrm{c}}$ are the cross-sectional areas of the steel tube and concrete, respectively. The obtained effective axial $\sigma-\varepsilon$ curves of steel are compared in Fig. 1a for columns with different $\xi_{\mathrm{c}}$-values. It can be clearly seen that the effective $\sigma-\varepsilon$ curves obtained from the 3D FE modelling are quite different from the input $\sigma-\varepsilon$ curve. This is due to the development of hoop stresses in the steel tube in combination with the influence of local buckling of the steel tube. The analysed examples highlight the need to develop an effective $\sigma-\varepsilon$ model of steel for the FBE modelling of rectangular CFST columns.

In general, the effective $\sigma-\varepsilon$ curves of steel in different columns follow a same linear relationship in the elastic stage. This is due to the weak interaction between the steel tube and core concrete in this stage [1]. But after

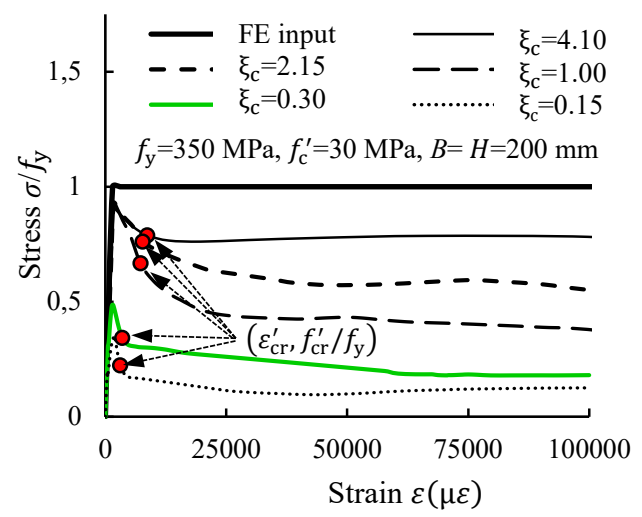

(a) Steel $\sigma-\varepsilon$ curves reaching the peak stress, the effective $\sigma-\varepsilon$ curves enter into the post-peak stage. Depending on the $\xi_{\mathrm{c}}$-value, the descending speeds of the curves are different. The smaller the $\xi_{\mathrm{c}}$-value, the faster the curve descends. Similar observation has been reported by Katwal et al. [6] for circular CFST columns, which can be explained by the dilation effect of the concrete and the local buckling of the steel tube. For circular CFST columns, strainhardening was observed beyond the critical point $\left(\varepsilon_{\mathrm{cr}}^{\prime}, f_{\mathrm{cr}}^{\prime} / f_{\mathrm{y}}\right)$ on the curve [6]. However, for rectangular CFST columns, no such strainhardening can be found in the curves shown in Fig. 1a. This is due to the fact that steel tubes in rectangular CFST columns are more susceptible to local buckling compared to the steel tubes in the circular counterparts [1].

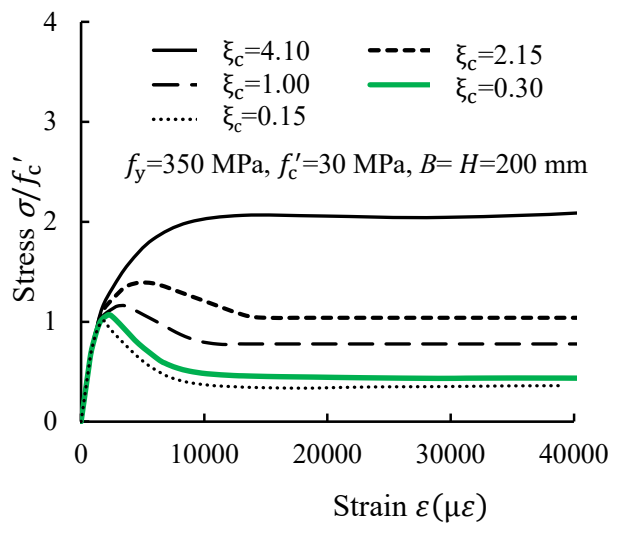

(b) Concrete $\sigma-\varepsilon$ curves

Fig. 1. Effective $\sigma-\varepsilon$ curves of steel and concrete.

\subsubsection{Proposed steel relationship}

The effective $\sigma-\varepsilon$ model of steel expressed by Eq. (1) was originally proposed by Katwal et al. [6] for circular CFST columns.

$\sigma=\left\{\begin{array}{lr}E_{\mathrm{s}} \varepsilon & 0 \leq \varepsilon<\varepsilon_{y}^{\prime} \\ f_{\mathrm{cr}}^{\prime}-\left(f_{\mathrm{cr}}^{\prime}-f_{y}^{\prime}\right) \cdot\left(\frac{\varepsilon_{\mathrm{cr}}^{\prime}-\varepsilon}{\varepsilon_{\mathrm{cr}}-\varepsilon_{y}^{\prime}}\right)^{\psi} & \varepsilon_{y}^{\prime} \leq \varepsilon<\varepsilon_{\mathrm{cr}}^{\prime} \\ f_{\mathrm{u}}^{\prime}-\left(f_{\mathrm{u}}^{\prime}-f_{\mathrm{cr}}^{\prime}\right) \cdot\left(\frac{\varepsilon_{\mathrm{u}}-\varepsilon}{\varepsilon_{\mathrm{u}}-\varepsilon_{\mathrm{cr}}^{\prime}}\right)^{p} & \varepsilon_{\mathrm{cr}}^{\prime} \leq \varepsilon<\varepsilon_{\mathrm{u}} \\ f_{\mathrm{u}}^{\prime} & \varepsilon \geq \varepsilon_{\mathrm{u}}\end{array}\right.$

where $E_{\mathrm{s}}$ is the Young's modulus of steel; $f_{\mathrm{y}}^{\prime}$ is the first peak stress of steel in the CFST column; $\varepsilon_{\mathrm{y}}^{\prime} \quad\left(=f_{\mathrm{y}}^{\prime} / E_{\mathrm{s}}\right)$ is the strain corresponding to $f_{y}^{\prime} ; \psi$ and $p$ are the strain softening exponents; $\varepsilon_{\text {cr }}^{\prime}$ and $f_{\text {cr }}^{\prime}$ are the critical strain and stress respectively; and $f_{\mathrm{u}}^{\prime}$ is the effective stress of steel corresponding to the ultimate strain $\left(\varepsilon_{\mathrm{u}}\right)$. It is found that Eq. (1) can also be used for rectangular CFST columns if the parameters in the equation are recalibrated using the numerical data of rectangular CFST columns. Fig. 2 shows a schematic view of the simplified effective $\sigma-$ $\varepsilon$ curves with low, medium and high $\xi_{\mathrm{c}}$ values for rectangular CFST columns. Six parameters $\left(f_{\mathrm{y}}^{\prime}, f_{\mathrm{cr}}^{\prime}, \varepsilon_{\mathrm{cr}}^{\prime}, f_{\mathrm{u}}^{\prime}, \psi\right.$, and $\left.p\right)$ specifying the effective $\sigma-\varepsilon$ relationship need to be determined or recalibrated. 


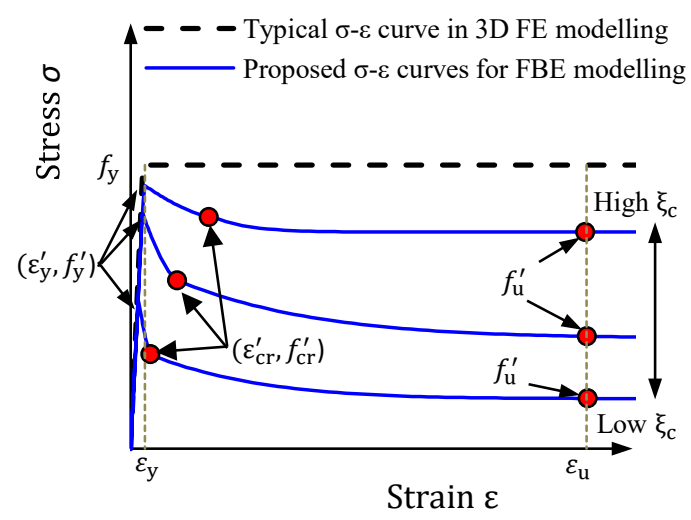

Fig. 2. Proposed steel $\sigma-\varepsilon$ curves for FBE modelling of rectangular CFST columns.

It is found that $f_{\mathrm{y}}^{\prime}$ can be calculated using Eq. (2) proposed by Wang et al. [8].

$$
\begin{aligned}
f_{\mathrm{y}}^{\prime}=f_{\mathrm{y}} \cdot\left[0.91+7.31 \times 10^{-5} f_{\mathrm{y}}-\right. \\
\left.\quad\left(1.28 \times 10^{-6}+2.26 \times 10^{-8} f_{\mathrm{y}}\right)\left(\frac{D^{\prime}}{t}\right)^{2}\right]
\end{aligned}
$$

where $D^{\prime}$ is the equivalent diameter defined as $\sqrt{B^{2}+H^{2}}$. Eqs. (3)-(5) are proposed in this study to determine $f_{\mathrm{cr}}^{\prime}, \varepsilon_{\mathrm{cr}}^{\prime}$, and $f_{\mathrm{u}}^{\prime}$, respectively. These equations were derived based on regression analysis of the numerical data generated from 3D FE modelling.

$$
\begin{gathered}
f_{\mathrm{cr}}^{\prime}=f_{\mathrm{y}} \cdot\left(2.15 \xi_{\mathrm{c}}^{0.02}-0.002 \frac{D^{\prime}}{t}-1.35\right) \\
\varepsilon_{\mathrm{cr}}^{\prime}=\varepsilon_{\mathrm{y}} \cdot\left[6.5-0.035 \frac{D^{\prime}}{t}\left(1-0.0015 \frac{D^{\prime}}{t}\right)\right. \\
\left.+0.06 \xi_{\mathrm{c}}\right] \\
f_{\mathrm{u}}^{\prime}=f_{\mathrm{y}} \cdot\left[1.2 \xi_{\mathrm{c}}^{0.02}-0.2\left(\frac{D^{\prime}}{t}\right)^{0.3}\right]
\end{gathered}
$$

The value of $\psi$ was suggested by Katwal et al. [6] as 1.5 for circular CFST columns. The same value is found to be applicable for rectangular CFST columns as well. Since the steel effective $\sigma-\varepsilon$ relationship for rectangular CFST columns does not have a strength recovery in the post-peak stage, the equation to determine $p$ is recalibrated and given by Eq. (6).

$$
p=-0.02 E_{\mathrm{s}}\left(\frac{\varepsilon_{\mathrm{u}}-\varepsilon_{\mathrm{cr}}^{\prime}}{f_{\mathrm{u}}^{\prime}-f_{\mathrm{cr}}^{\prime}}\right)
$$

\subsection{Proposed Concrete Model}

\subsubsection{Characteristics of stress-strain curves for concrete}

For the concrete infill in a CFST column, the compressive strength and ductility can be improved as a result of confinement. The confinement factor $\xi_{c}$ can reasonably reflect the intensity of concrete confinement [1]. Effective concrete $\sigma-\varepsilon$ curves for rectangular CFST columns with different $\xi_{\mathrm{c}}$ values are obtained from 3D FE modelling and compared in Fig. 1b. When the confinement is strong, an obvious increase in compressive strength and ductility can be obtained for the concrete. But when $\xi_{\mathrm{c}}$ is small, the increase in strength and ductility of the concrete is limited due to the relatively weak confinement. An effective concrete $\sigma-$ $\varepsilon$ relationship is proposed in the following subsection to consider the confinement effect in rectangular CFST columns.

\subsubsection{Proposed concrete stress $\rightarrow$ strain relationship}

Eq. (7) was proposed by Katwal et al. [6] to represent the concrete stress-strain relationship for circular CFST columns. It is found that the same expression is also applicable for rectangular CFST columns.

$$
\sigma=\left\{\begin{array}{c}
\frac{A \cdot X+B \cdot X^{2}}{1+(A-2) \cdot X+(B+1) \cdot X^{2}} \cdot f_{\mathrm{cc}}^{\prime} \\
X \leq 1 \text { or }\left(X>1 \text { and } \sigma>f_{\mathrm{r}}\right) \\
f_{\mathrm{r}} \quad X>1 \text { and } \sigma \leq f_{\mathrm{r}} \\
X=\frac{\varepsilon}{\varepsilon_{\mathrm{cc}}^{\prime}}
\end{array}\right.
$$

where $f_{\mathrm{cc}}^{\prime}$ and $\varepsilon_{\mathrm{cc}}^{\prime}$ are the confined concrete strength and the corresponding ultimate strain; $f_{\mathrm{r}}$ is the residual stress of concrete; and $A$ and $B$ are the coefficients to determine the shape of the $\sigma-\varepsilon$ curve. Fig. 3 shows the schematic of $\sigma-\varepsilon$ curves with low and high $\xi_{\mathrm{c}}$ values. Five parameters $\left(f_{\mathrm{cc}}^{\prime}, \varepsilon_{\mathrm{cc}}^{\prime}, f_{\mathrm{r}}, A\right.$, and $\left.B\right)$ are required to define the full-range $\sigma-\varepsilon$ relationship of concrete.

To determine $f_{\mathrm{cc}}^{\prime}$ and $\varepsilon_{\mathrm{cc}}^{\prime}$, the equations proposed by Wang et al. [8] are utilised in the present study which are represented by Eqs. (9) and (11), respectively. 


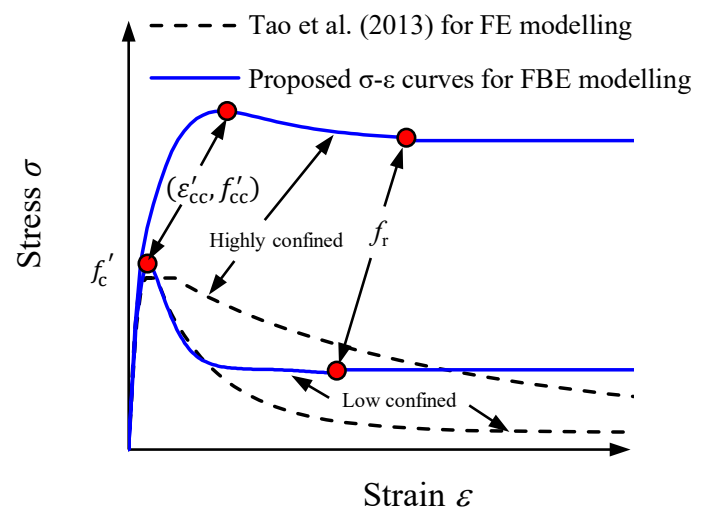

Fig. 3. Proposed concrete $\sigma-\varepsilon$ curves for FBE modelling of rectangular CFST columns.

$$
f_{\mathrm{cc}}^{\prime}=f_{\mathrm{c}}^{\prime}\left[0.98+\frac{29.5}{f_{\mathrm{y}}^{0.48}} k_{\mathrm{s}}^{0.2}\left(\frac{t f_{\mathrm{y}}}{D^{\prime} f_{\mathrm{c}}^{\prime}}\right)^{1.3}\right]
$$

where $k_{\mathrm{s}}$ is the equivalent confining coefficient proposed by Lam and Teng [9]

$$
\begin{aligned}
& k_{\mathrm{s}}=\frac{1}{3}\left(\frac{B-2 t}{H-2 t}\right)^{2} \\
& \varepsilon_{\mathrm{cc}}^{\prime}=2300+ 31.2 f_{\mathrm{c}}^{\prime}+\left(2.32 \times 10^{4}\right. \\
&-3.88 \\
& \times 10^{6} f_{\mathrm{c}}^{\prime-1.8}\left(\frac{t f_{\mathrm{y}}}{D^{\prime} f_{\mathrm{c}}^{\prime}}\right)^{2}
\end{aligned}
$$

Based on regression analysis, Eq. (12) is proposed to determine $f_{\mathrm{r}}$ for rectangular CFST columns.

$$
f_{\mathrm{r}}=f_{\mathrm{cc}}^{\prime}\left(\sqrt{\frac{t}{D^{\prime} f_{\mathrm{c}}^{\prime}}}+\frac{\sqrt{\xi_{\mathrm{c}}}}{2}\right) \leq f_{\mathrm{cc}}^{\prime}
$$

Also based on regression analysis, Eqs. (13) and (14) are proposed to calculate $A$ and $B$, respectively.

$$
A=\alpha_{1} \frac{E_{\mathrm{c}} \varepsilon_{\mathrm{cc}}^{\prime}}{f_{\mathrm{cc}}^{\prime}}
$$

where $\quad \alpha_{1}=1+0.2 \cdot \xi_{\mathrm{c}}^{\left(0.05+0.2 / \xi_{\mathrm{c}}\right)}$; and $E_{\mathrm{c}}$ is the modulus of elasticity of concrete.

$$
B=-0.005-0.7 e^{\left(-0.3 \xi_{\mathrm{c}}^{3}\right)} \geq-0.75
$$

It should be noted that Eqs. (1) and (7) are only applicable for steel and concrete under compression. This paper intends to develop FBE models not only for stub columns under axial compression, but also for slender columns, beams and beam-columns, where part of the materials is likely subjected to tension. Therefore, the tensile material properties of steel and concrete need to be defined for simulation. For steel in tension, the $\sigma-\varepsilon$ relationship proposed by Tao et al. [10] is used in this study. As for concrete in tension, the tensile $\sigma-\varepsilon$ relationship proposed by Hassan [11] is used in the present study.

\section{Validation of the Simplified Model}

Test results of rectangular CFST stub columns, beams, slender columns, and beamcolumns reported in the literature are used to verify the accuracy of the proposed material models for FBE modelling. Detailed comparisons between the predicted and measured results are given in the following subsections.

\subsection{Stub Columns}

The axial load-axial strain $(N-\varepsilon)$ curves of 180 rectangular CFST stub columns collected from 21 sources were used to verify the proposed FBE model. Those test data were originally collected by Tao et al. [7] to develop 3D FE models, and the data cover a wide range of parameters: $f_{\mathrm{y}}=194-835 \mathrm{MPa}$; $f_{\mathrm{c}}^{\prime}=20-160 \mathrm{MPa} ; \quad B=60-500 \mathrm{~mm}$; and $D^{\prime} / t=14-212$.

Firstly, the predicted ultimate strengths $\left(N_{\text {uc }}\right)$ are compared with the measured ultimate strengths $\left(N_{\text {ue }}\right)$ in Fig. 4. Following the definition proposed by Tao et al. [7], the ultimate strength in this study is taken as the peak load if the $N-\varepsilon$ curve has a softening branch and the strain corresponding to the peak load is less than 0.01 ; otherwise the ultimate strength is defined as the load at 0.01 . The mean $(\mu)$ and standard deviation $(S D)$ of the $N_{\text {uc }} / N_{\text {ue }}$ ratio are 0.951 and 0.073 , respectively. This indicates a good correlation between the predicted and measured ultimate strengths. The predicted $N-\varepsilon$ curves are also compared with the measured curves of rectangular CFST stub columns. In general, the agreement between them is also very good. Due to the space limitation, only a few representative results are presented in this paper. 
Katwal et al. [6] divided circular CFST columns into different groups based on the steel and concrete strengths. The concrete was classified into three categories: normal strength concrete (NSC: $f_{\mathrm{c}}^{\prime} \leq 60 \mathrm{MPa}$ ), high strength concrete (HSC: $60 \mathrm{MPa}<f_{\mathrm{c}}^{\prime} \leq$ $120 \mathrm{MPa}$ ) and ultra-high strength concrete (UHSC: $f_{\mathrm{c}}^{\prime}>120 \mathrm{MPa}$ ). Similarly, the steel was classified into two categories: normal strength steel(NSS: $f_{\mathrm{y}} \leq 460 \mathrm{MPa}$ ) and high strength steel (HSS: $f_{\mathrm{y}}>460 \mathrm{MPa}$ ). This classification method is also applied to rectangular CFST columns in this study.

Fig. 5 compares the predicted and measured $N-\varepsilon$ curves of a typical specimen $4 \mathrm{HN}$ with NSC and NSS, which was tested by Tomii et al. [12]. It can be seen that the predicted curve agrees very well with the measured curve and the curve predicted from the 3D FE modelling. The initial stiffness, ultimate strength, strength deterioration as well as the residual strength are well predicted by the FBE modelling. Based on the simulation, the loads carried by the steel tube and concrete are also presented in Fig. 5. Because the concrete has more contribution to the ultimate strength than the steel tube, this specimen has a high descending speed when entering into the post-peak stage.

To verify the prediction accuracy of the proposed FBE model for HSS tubes filled with HSC or UHSC, two specimens CR8-A-8 and $\mathrm{S} 2$ tested by Sakino et al. [2] and Xiong et al. [13], respectively, are selected for demonstration. The values of $f_{\mathrm{y}}$ for CR8-A-8 and $\mathrm{S} 2$ are 835 and $779 \mathrm{MPa}$ and the corresponding values of $f_{\mathrm{c}}^{\prime}$ are 74.8 and 152.4 $\mathrm{MPa}$, respectively. The comparisons shown in Figs. 6 (specimen CR8-A-8) and 7 (specimen S2) indicate very good predictions by the FBE modeling.

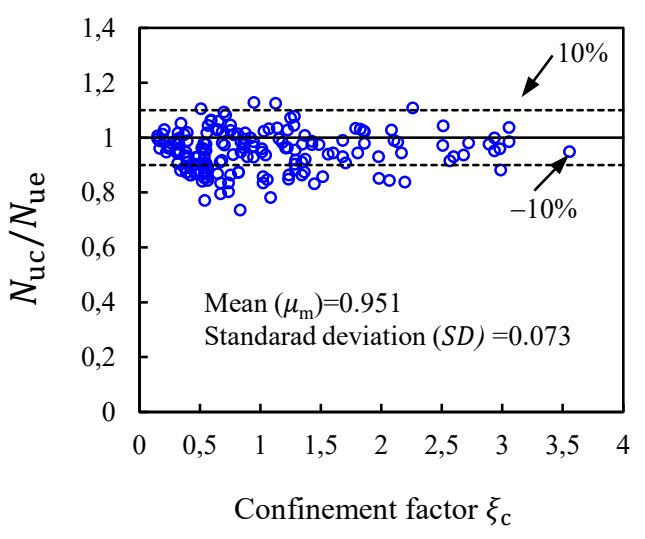

Fig. 4. Comparison between $N_{\mathrm{uc}} / N_{\text {ue }}$ with respect to $\xi_{\mathrm{c}}$ for CFST stub columns.

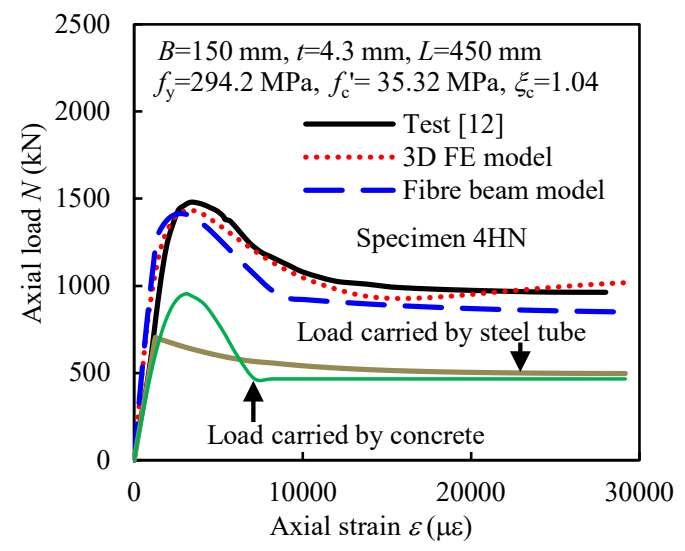

Fig. 5. Comparison of predicted and measured $N-\varepsilon$ curves for a typical specimen with NSC and NSS.

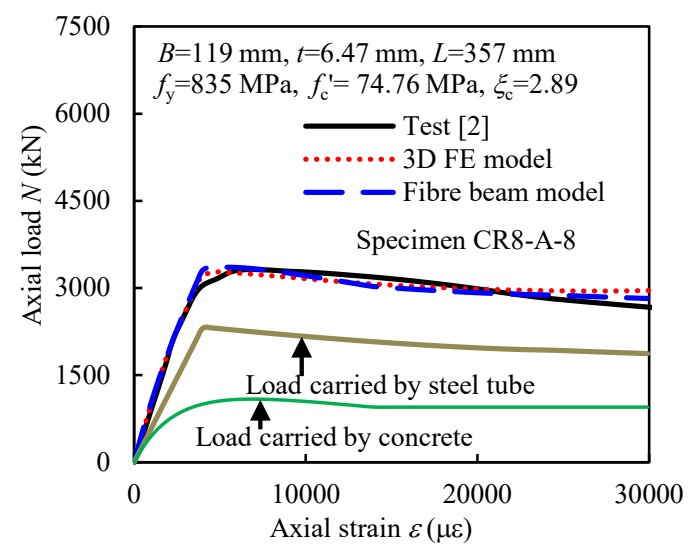

Fig. 6. Comparison of predicted and measured $N-\varepsilon$ curves for a typical specimen with HSC and HSS. 


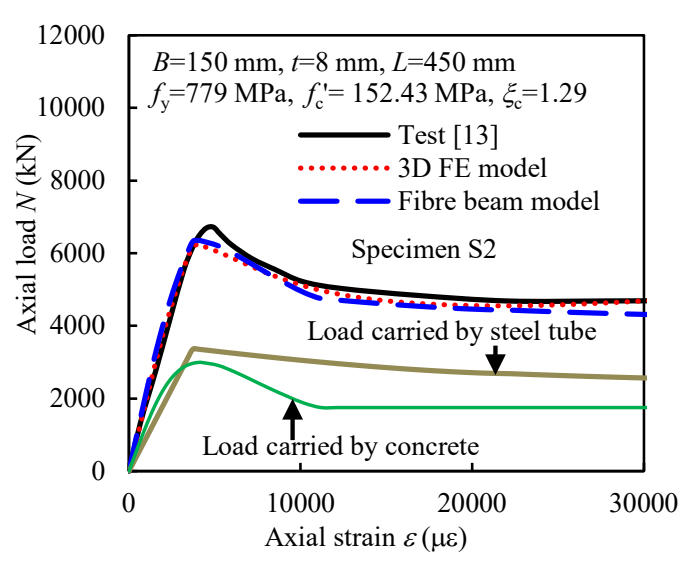

Fig. 7. Comparison of predicted and measured $N-\varepsilon$ curves for a typical specimen with UHSC and HSS.

\subsection{Beams}

Twelve CFST beams under pure bending tested by Gho and Liu [14] were selected to verify the proposed FBE model in simulating CFST beams. These specimens were simplysupported with one end hinged and the other end roller supported. Two point loads were applied at one-quarter of the span from each side. The span of the beams were $1460 \mathrm{~mm}$. In general, reasonable prediction accuracy was obtained from the FBE modelling for all the twelve beams. The comparison between predicted and measured mid-span moment versus mid-span deflection $(M-\delta)$ for two typical specimens B02 and B10 are presented in Fig. 8. It can be seen that the predictions obtained from the FBE modelling are in good agreement with the test data.

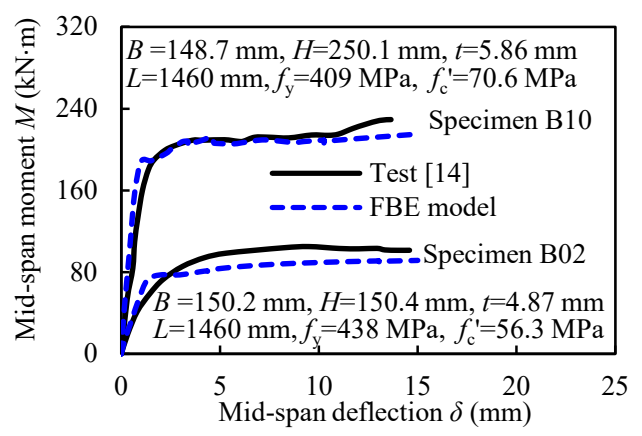

Fig. 8. Comparison of predicted and measured $M-\delta$ curves for a typical CFST beam.

\subsection{Slender columns}

Initial imperfections cause significant strength reduction for slender columns due to the second-order effect. Therefore, initial imperfections are included in this study to simulate slender CFST columns. This is achieved by scaling the first eigenvalue buckling mode shape. The amplitude of the imperfections is tentatively taken as $L / 1000$ in the present study, where $L$ is the length of the column. Further research can be conducted to determine more suitable values of the imperfection amplitude to improve the prediction accuracy.

Eight test data reported by Han et al. [15] are used in the present study to verify the proposed FBE model in simulating slender columns. In general, the axial load versus mid-span deflection $\left(N-u_{\mathrm{m}}\right)$ curves have been predicted reasonably well for all the selected slender columns. An example is presented in Fig. 9 for specimen scp2-1-1 with a slenderness ratio $(\lambda)$ of 75 . The ultimate strength of this specimen is underestimated by $8.8 \%$, but the shape of the predicted curve agrees very well with that of the test curve.

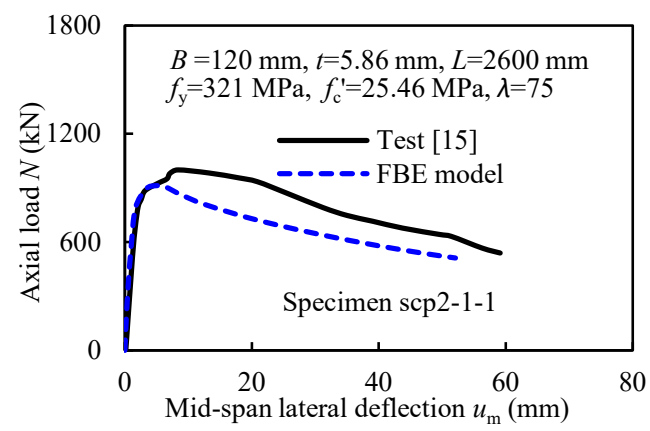

Fig. 9. Comparison of predicted and measured $N-u_{\mathrm{m}}$ curves for a typical slender column.

\subsection{Beam-columns}

The FBE model is further verified by test data of beam-columns reported by Han et al. [15]. Initial imperfections are also considered in the FBE modelling. The $N-u_{\mathrm{m}}$ curves predicted from the FBE modelling and 3D FE modelling are compared in Fig. 10 with the measured curve of a typical beam-column specimen scp1-2-4. The predicted ultimate strength from the FBE modelling is $15.0 \%$ smaller than the measured strength and 5.9\% smaller than the 3D FE prediction. It should be noted that the material models developed in Section 3 were based on CFST columns under concentric compression. The direct use of these models indicates the omission of any strain gradient effect, which may lead to the conservative prediction for scp1-2-4. Further 
research is required to improve the prediction accuracy for beam-columns using FBE modelling.

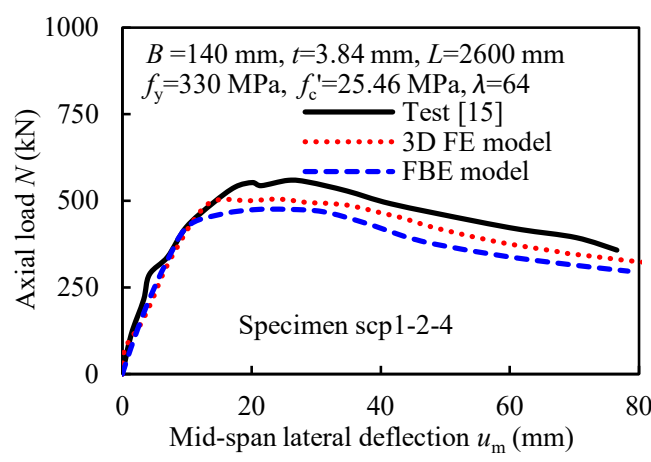

Fig. 10. Comparison of predicted and measured $N-u_{\mathrm{m}}$ curves for a typical beam-column.

\section{Concluding remarks}

In this paper, effective steel and concrete stress-strain models have been proposed for rectangular concrete-filled steel tubular columns based on detailed finite element modelling of stub columns under axial compression. The proposed stress-strain curves for steel have implicitly considered the interaction between the steel tube and concrete as well as local buckling of the steel tube. Meanwhile, the concrete model has considered the increase in strength and ductility resulting from the confinement.

The proposed material models were implemented in simplified fibre beam element modelling, and the predictions were verified by detailed FE modelling and a large amount of test data on rectangular CFST stub columns, beams, slender columns, and beam columns collected from the literature.

Further research can be conducted to account for the influence of global imperfections on slender columns and beamcolumns and strain gradient effect. Moreover, this work can be extended to CFST columns with other cross-sectional shapes, e.g. polygonal, elliptical, etc. Because of the efficiency of FBE modelling, it is suitable to be used to analyse composite frames with CFST columns subjected to extreme events, such as fire, earthquakes, impact and blast. Further research is required in these areas.

\section{References}

[1] Han LH, Li W, Bjorhovde R. Developments and advanced applications of concrete-filled steel tubular (CFST) structures: Members. Journal of Constructional Steel Research 2014;100: 211-228.

[2] Sakino K, Nakahara H, Morino S, Nishiyama I. Behavior of centrally loaded concrete-filled steel-tube short columns. Journal of Structural Engineering, ASCE 2004;130: 180-188.

[3] Liang QQ, Uy B, Liew JYR. Nonlinear analysis of concrete-filled thin-walled steel box columns with local buckling effects. Journal of Constructional Steel Research 2006;62: 581-591.

[4] Thai HT, Uy B, Khan M. A modified stressstrain model accounting for the local buckling of thin-walled stub columns under axial compression. Journal of Constructional Steel Research 2015;111: 57-69.

[5] Lai Z, Varma AH. Effective stress-strain relationships for analysis of noncompact and slender filled composite (CFT) members. Engineering Structures 2016;124: 457-472.

[6] Katwal U, Tao Z, Hassan MK, Wang WD. Simplified numerical modelling of axially loaded circular concrete-filled steel stub columns. Journal of Structural Engineering, ASCE 2017;143(12): 04017169(1-12).

[7] Tao Z, Wang ZB, Yu Q. Finite element modelling of concrete-filled steel stub columns under axial compression. Journal of Constructional Steel Research 2013;89: 121-131.

[8] Wang ZB, Tao Z, Han LH, Uy B, Lam D, Kang WH. Strength, stiffness and ductility of concrete-filled steel columns under axial compression. Engineering Structures 2017; 135: 209-221.

[9] Lam L, Teng JG. Design-oriented stress-strain model for FRP-confined concrete in rectangular columns. Journal of Reinforced plastic composites 2003;22(13): 1149-1186.

[10] Tao Z, Wang XQ, Uy B. Stress-strain curves of structural and reinforcing steels after exposure to elevated temperatures. Journal of Materials in Civil Engineering 2013;25(9): 1306-1316.

[11]Hassan MK. Behaviour of hybrid stainlesscarbon steel composite beam-column joints. $\mathrm{PhD}$ thesis, Western Sydney University, Sydney, Australia; 2016.

[12] Tomii M, Yoshimura K, Morishita Y. Experimental studies on concrete filled steel tubular stub columns under concentric loading. Proceedings of the International Colloquium on Stability of Structures under 
Static and Dynamic Loads. Washington DC, USA; 1977.

[13]Xiong MX, Xiong DX, Liew JYR. Axial performance of short concrete filled steel tubes with high- and ultra-high-strength materials. Engineering Structures 2017;136(4): 494-510.
[14] Gho WM, Liu D. Flexural behaviour of highstrength rectangular concrete-filled steel hollow sections. Journal of Constructional Steel Research 2004;60: 1681-1696.

[15] Han LH, Zhao XL, Tao Z. Tests and mechanics model for concrete-filled SHS stub columns, columns and beam-columns. Steel and Composite Structures 2001;1(1): 51-74. 